\title{
The Prevalence of Migraine in Iran: A Systematic Review and Meta-Analysis
}

\author{
Zeynab Farhadi, ${ }^{1}$ Saeideh Alidoost, ${ }^{2}$ Meysam Behzadifar, ${ }^{3}$ Roghayeh Mohammadibakhsh, ${ }^{4}$ Najmeh \\ Khodadadi, ${ }^{5}$ Razieh Sepehrian, ${ }^{6}$ Rahim Sohrabi, ${ }^{7}$ Masood Taheri Mirghaed, ${ }^{6}$ Morteza Salemi, ${ }^{8}$ Hamid \\ Ravaghi, ${ }^{6}$ and Masoud Behzadifar ${ }^{2,3,6,{ }^{*}}$ \\ ${ }^{1}$ School of Medicine, Babol University of Medical Sciences, Babol, IR Iran \\ ${ }^{2}$ Health Management and Economics Research Center, Iran University of Medical Sciences, Tehran, IR Iran \\ ${ }^{3}$ Department of Public Health, Faculty of Health and Nutrition, Lorestan University of Medical Sciences, Khorramabad, IR Iran \\ ${ }^{4}$ Hamadan University of Medical Sciences, Hamadan, IR Iran \\ ${ }^{5}$ Mashhad University of Medical Sciences, Mashhad, IR Iran \\ ${ }^{6}$ Department of Health Services Management, School of Health Management and Information Sciences, Iran University of Medical Sciences, Tehran, IR Iran \\ ${ }^{7}$ Iranian Social Security Organization, Zanjan Province Health Administration, Zanjan, IR Iran \\ ${ }^{8}$ Social Determinants in Health Promotion Research Center, Hormozgan University of Medical Sciences, Bandar Abbas, IR Iran \\ "Corresponding author: Masoud Behzadifar, Health Management and Economics Research Center, Iran University of Medical Sciences, Tehran, IR Iran. E-mail: \\ masoudbehzadifar@gmail.com; behzadifar.m@tak.iums.ac.ir
}

Received 2016 June 15; Revised 2016 August 20; Accepted 2016 September 13.

\begin{abstract}
Context: Migraine is a major dilemma and problem which affects public health and results to reduced quality of life. This study aimed to determine the prevalence of migraine in Iran.

Evidence Acquisition: A systematic search was conducted using Pub Med, Web of Science, Embase, Scopus, Ovid, Google Scholar, as well as Iranian databases including: MagIran, IranMedex and Scientific Information Databank, from 2000 to November, 2015. The Der-Simonian/Laird's random-effects model, with a 95\% confidence interval was employed to estimate the overall pooled prevalence. Heterogeneity was investigated using subgroup analysis based on sample size and time of study.

Results: Thirty studies comprising 33,873 participants met the inclusion criteria for the analysis. The overall prevalence of migraine in Iran was $14 \%$ (95\% CI, $12 \%$ to $17 \%$ ), respectively. The overall prevalence was (8\%; $95 \%$ CI $6 \%$ to $11 \%$ ) according to the international classification of headache disorders (ICHD-1), (17\%; 95\% CI 13\% to 21\%) according to ICHD-2, and (18\%; 95\% CI 7\% to 30\%) according to the other questionnaire for migraine screener (ID Migraine), respectively. Meta-regression demonstrated that the prevalence of migraine increased by year of publication and decreased by sample size.

Conclusions: The prevalence of migraine in Iran, which was estimated as $14 \%$, was similar or even higher than that reported worldwide. Migraine can have impact on the economic productivity of any country; therefore it is necessary to educate people on the early detection and the discovery of an effective treatment of migraine. More thorough review of further studies in this field is recommended.
\end{abstract}

Keywords: Meta-Analysis, Migraine, Prevalence, Iran

\section{Context}

Headaches are one of the most common diseases worldwide, and they occur in all age groups, from childhood to old age. Almost everyone experiences headache in life (1). Primary disorders of headache include migraine and tension-headaches (2). Migraine is a chronic neurovascular disorder in the brain. Migraine headache is commonly throbbing and unilateral, and it is associated with photophobia, phonophobia and/or nausea. It could be so severe that it interferes with daily activity (3). People with migraines suffer from pains and attacks which result from the disease. Exposure to sun, stress, anxiety, sleep disorders, multiple trips, eating habits, fatigue, smoking and low levels of economic life are important risk factors associated with migraine (4). Migraine is a major dilemma and problem of public health which leads to reduced quality of life. It also adversely affects the individual, family and social activities (5). People between the ages of 10 to 40 , who are considered as part of the economically active workforce in every country, are more prone to migraine attacks (6). Costs arising from the treatment of migraine have great effect on the economy of any country, and due to 
the disability in the individual caused by the disease; there is decrease in the production and productivity of the active workforces of the society $(5,6)$. Studies have shown that the prevalence rate of migraines in the world is between 10 and $18 \%$ (4). In Western countries, about $12 \%$ of the total populations are affected by migraine, with females being three times more prone to this disease than males (7). According to the global of burden disease (GBD) in 2013, migraine is the sixth leading cause of disabilities in the world (8). In recent years, several studies on the prevalence of migraine in different population groups in Iran have been conducted. The present study aimed to determine a general estimate of the prevalence of migraine in Iran and also to assess the general trend of the problem. This study is the first systematic review and meta-analysis of migraine prevalence in Iran. The results of this study may be helpful in enlightening policy makers and authorities regarding the real situation and necessity of adopting effective policies and programs for the purpose of reducing migraine in Iran.

\section{Evidence Acquisition}

\subsection{Data Source}

Two authors carried out an independent international databases search, including Pub Med, Web of Science (ISI), Embase, Scopus, Ovid, Google Scholar, while the Iranian databases search included MagIran, IranMedex and Scientific Information Databank (SID). This search was conducted up to November, 2015. Databases were searched using the Mesh terms like "Prevalence", "Migraine" and related terms of studies published in Persian and English languages. References of articles were also checked for any relevant articles. Figure 1 shows the literature search in accordance with the Preferred Reporting Items for Systematic Reviews and Meta-Analyses (PRISMA) (9).

\subsection{Study Selection}

Inclusion criteria were: Studies which reported rate of migraine prevalence among an Iranian-based population, studies which utilized the International system of classification of headache disorder (ICHD) criteria or screening tools for the prevalence of migraine, case-control studies or cohort studies. The exclusion criteria were: unknown sample origins, unclear results and methods, use of case reports and case series design, studies in which the treatment was intended, studies which reported migraine incidence among non-Iranian nationality, meta-analysis, reviews, meeting abstract or editorial comments, and studies having duplicate data.
Articles were independently screened by two authors for relevance, and conflicts were resolved by discussion and a third author.

\subsection{Data Extraction}

Variables extracted for each study included: First author's name, publication year, location of studies, age, the gender of the participants, sample size, number of cases, screening method, STROBE quality and diagnostic criteria. Assessment of the quality of the studies was done using strengthening the reporting of observational studies in epidemiology (STROBE) checklist (10). The base checklists of STROBE for the studies were classified in three categories which included high, intermediate and low quality. Seven items from the recommended checklist of STROBE were selected and used for assessing the quality of studies. These items included: present the key elements of the study design, clearly define the outcome of migraine, give the eligibility criteria, explain how the study sample was arrived at, describe the setting, locations, and relevant dates, give sources of data and details of methods of assessment, and describe all statistical methods. The studies were classified as high quality if all items were achieved, as intermediate quality if they did not achieve one criterion, and as low quality if they did not achieve more than one criterion.

\subsection{Statistical Analysis}

A pooled estimated prevalence of migraine was generated using Der-Simonian and Laird's random-effects model. The reported effective estimate with 95\% confidence interval (CI) variance for the studies was calculated using the Binomial distribution formula. Statistical heterogeneity was assessed among the studies using Chisquare-based Q test and $\mathrm{I}^{2}$ (11).

All statistical significances were at P-values less than 0.05. The sources of heterogeneity were obtained using meta-regression which was analyzed on the prior knowledge of effective factors, such as sample size and publication year. Also, subgroup analysis by sample size, diagnostic criteria, groups, geographical region, and quality of the studies was done to obtain the source of heterogeneity. A sensitivity analysis was performed to determine the effect of each study on the prevalence of migraine by sequentially omitting each data set. Egger's test and funnel plot was used to assess publication bias (12). All data were analyzed using STATA Ver.12 (Stata Corp, College Station, TX, USA).

\section{Results}

All databases (English and Persian) were searched from 2000 to 2015 (11 years), using the search keywords. The 


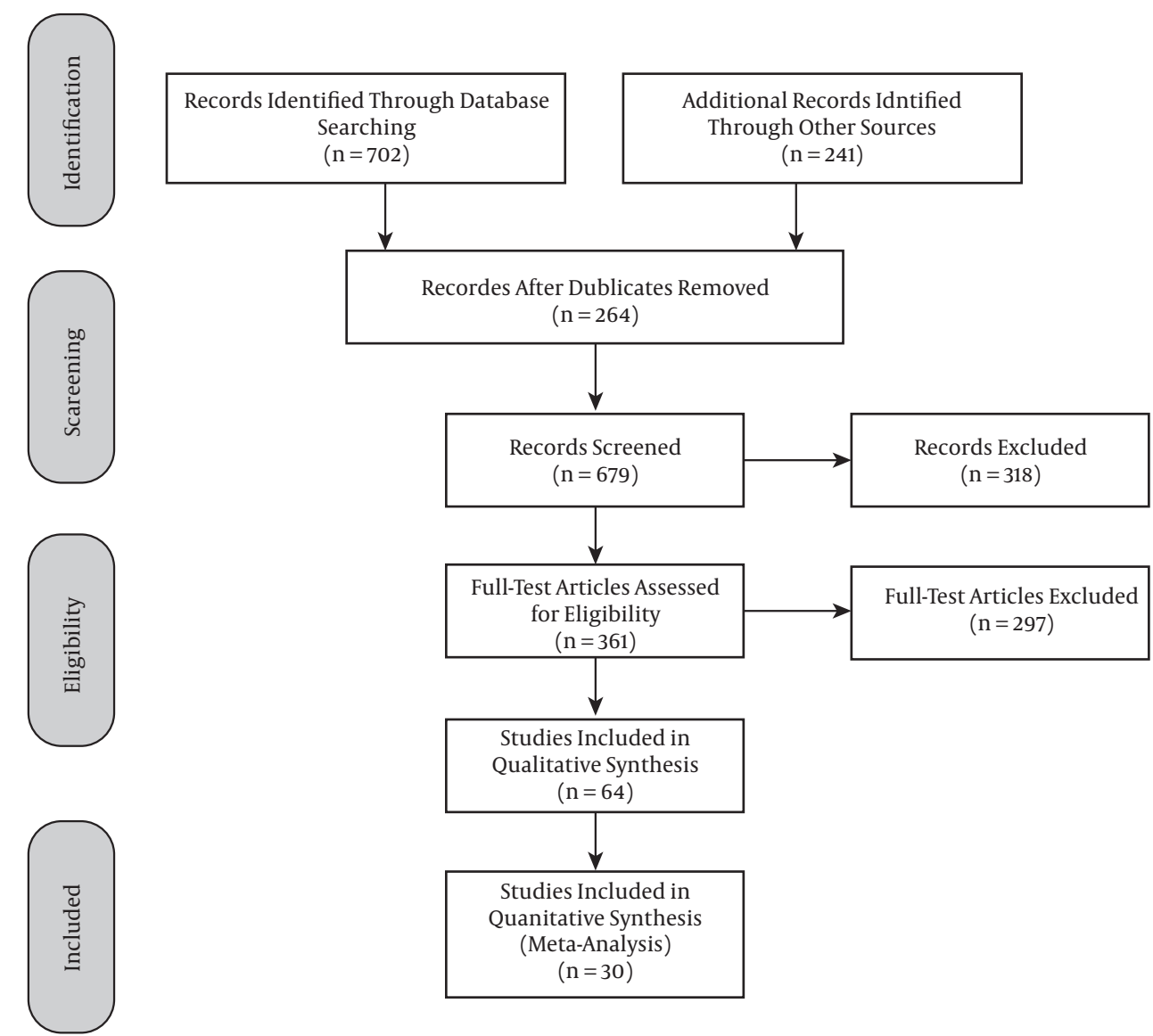

Figure 1. Flowchart of Search and Studies Selection

following search strategy" migraine" OR "headache" AND "prevalence" AND "Iran" were used. Two authors independently assessed the abstract and full-text studies and selected the studies using the inclusion and exclusion criteria. Finally, 30 articles which comprised 33,873 participants were included in this systematic review and meta-analysis study (13-42). The results of literature searches are shown in Figure 1 and Table 1 . The pooled prevalence of migraine, using the random-effects model in Iran, was 14\% (95\% CI $12 \%$ to17\%), and this is considered as significant $(\mathrm{P}<0.05)$ (Figure 2). The results of $\mathrm{Q}$ Cochran test $=2603.99$ and $\mathrm{I}^{2}=$ $98.9 \%$, d.f $=29$; $(\mathrm{P}<0.0000)$ showed the prevalence of migraine as being strongly heterogeneous among 30 studies. The minimum prevalence of migraine was $2 \%$ (95\% CI $1 \%$ to $2 \%$ ) according to Ayatollahi (2006) (22) in Shiraz, a town province, respectively, and the maximum prevalence of migraine was (46\%, 95\% CI $39 \%$ to $53 \%$ ) according to Tavasoli (2013) (38) in Tabriz town, respectively. The prevalence of migraine based on provinces in Iran is shown in Figure 3. Meta-regression showed that the prevalence of migraine increased by publication year and decreased by sample size (Table 2 and Figure 4). Based on analysis of the quality of studies which included meta-analysis, according to the STROB check list, it was observed that fifteen studies (50\%) were of high quality, eight studies (26.6\%) were of intermediate quality, and seven studies (23.4\%) were of low quality.

The results of the subgroup analysis showed the prevalence of migraine in Iran based sample size, diagnostic criteria, groups and geographical region, was performed.

The pooled prevalence was based on sample size as shown in Figure 5. The pooled prevalence was based on diagnostic criteria as shown in Figure 6. The pooled prevalence was based on groups of participants as shown in Figure 7. The pooled prevalence was based on geographical region as shown in Figure 8. The pooled prevalence was based on quality of studies as shown in Figure 9.

For robustness of result, sensitivity analysis was performed by eliminating each study. There was no significant change in the overall prevalence (Figure 10). Figure 11 shows the analyses of the publication bias of studies in re- 
Table 1. Characteristics of All Eligible Studies

\begin{tabular}{|c|c|c|c|c|c|c|}
\hline Author & Year & Cities & Sample Size & Diagnostic Criteria & Participants & Type of Study \\
\hline Yousefi & 1999 & Zanjan & 554 & ICHD-1 & Students & Cross-sectional \\
\hline Naderi & 2000 & Kerman, Isfahan, Sharekord & 700 & ICHD-2 & Students & Cross-sectional \\
\hline Ayatollahi & 2002 & Shiraz & 1868 & ICHD-1 & Population-based & Cross-sectional \\
\hline Mirzaee & 2004 & Sharehkord & 550 & ICHD-1 & Students & Cross-sectional \\
\hline Ghayeghran & 2004 & Rasht & 1965 & ICHD-1 & Students & Cross-sectional \\
\hline Moaiedi & 2004 & Bandar Abbas & 104 & ICHD-2 & Students & Cross-sectional \\
\hline Hashemilar & 2004 & Ardabil & 631 & ICHD-1 & Students & Cross-sectional \\
\hline Ayatollahi & 2005 & Shiraz & 538 & ICHD-2 & Teachers & Cross-sectional \\
\hline Bahrami & 2006 & Khoramabad & 2213 & Other questionnaire & Students & Cross-sectional \\
\hline Shahraki & 2006 & Zahedan & 1539 & Other questionnaire & Teachers & Cross-sectional \\
\hline Foroughi pour & 2006 & Mashhad & 423 & Other questionnaire & Population-based & Cross-sectional \\
\hline Ayatollahi & 2006 & Shiraz & 2226 & ICHD-1 & Students & Cross-sectional \\
\hline Sadreddini & 2006 & Tabriz & 340 & ICHD-2 & Students & Cross-sectional \\
\hline Sedighi & 2006 & Kerman & 4521 & ICHD-1 & Students & Cross-sectional \\
\hline Modara & 2008 & Ilam & 309 & ICHD-2 & Students & Cross-sectional \\
\hline Ayatollahi & 2009 & Shiraz & 1023 & ICHD-2 & Population-based & Cross-sectional \\
\hline Fallahzadeh & 2011 & Yazd & 930 & ICHD-1 & Students & Cross-sectional \\
\hline Khazaie & 2011 & Birjand & 723 & ICHD-1 & Students & Cross-sectional \\
\hline Shahraki & 2011 & Zahedan & 210 & ICHD-2 & Students & Cross-sectional \\
\hline Zangeneh & 2012 & Isfahan & 764 & ICHD-2 & Population-based & Cross-sectional \\
\hline Bahrami & 2012 & Khoramabad & 1000 & Other questionnaire & Population-based & Cross-sectional \\
\hline Zarei & 2012 & Jahrom & 1593 & Other questionnaire & Population-based & Cross-sectional \\
\hline Ghorbani & 2013 & Isfahan & 480 & ICHD-2 & Students & Cross-sectional \\
\hline Yazdanparast & 2013 & BandarAbbas & 350 & ICHD-2 & Students & Cross-sectional \\
\hline Shahbeigi & 2013 & Tehran & 3655 & ICHD-2 & Population-based & Cross-sectional \\
\hline Tavasoli & 2013 & Tabriz & 190 & ICHD-2 & Population-based & Cross-sectional \\
\hline Abdollahpour & 2010 & Boukan & 857 & ICHD-1 & Students & Cross-sectional \\
\hline Seyed Saadat & 2014 & Rasht & 541 & ICHD-2 & Population-based & Cross-sectional \\
\hline Ahmadpanah & 2014 & Hamadan & 1000 & ICHD-2 & Population-based & Cross-sectional \\
\hline Rabiee & 2015 & Tehran & 2076 & ICHD-2 & Population-based & Cross-sectional \\
\hline
\end{tabular}

Table 2. Meta-Regression Analysis of Prevalence of Migraine in Iran

\begin{tabular}{|c|c|c|c|c|c|c|}
\hline & \multirow[t]{2}{*}{ Coefficient } & \multirow[t]{2}{*}{ Standard Error } & \multirow[t]{2}{*}{$\mathbf{T}$} & \multirow[t]{2}{*}{$\mathbf{P}$} & \multicolumn{2}{|c|}{ Confidence Interval 95\% } \\
\hline & & & & & Lower & Upper \\
\hline Publication year & 0.0074331 & 0.0045972 & 1.62 & 0.118 & -0.0019996 & 0.0168659 \\
\hline Sample size & -0.0000157 & 0.0000191 & -0.82 & 0.419 & -0.0000549 & 0.0000235 \\
\hline Cons & -14.76564 & 9.23323 & -1.60 & 0.121 & -33.71066 & 4.179387 \\
\hline
\end{tabular}

view, using Egger's test and funnel plot. The results showed

that there existed publication bias among the studies $(\mathrm{P}=$ 


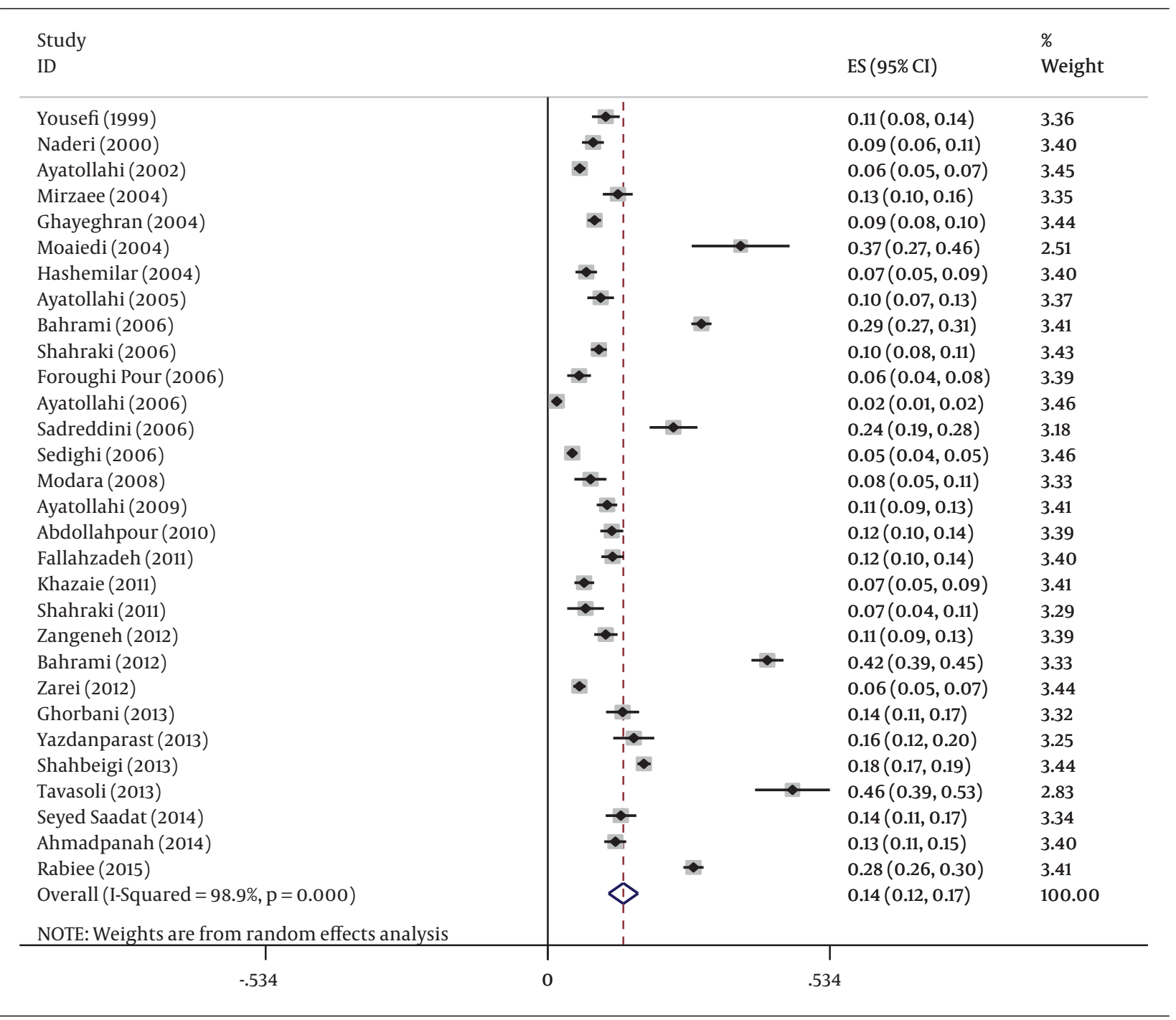

Figure 2. Forest Plot of Prevalence of Migraine in Iran Based on Diagnostic Criteria

0.000).

\section{Discussion}

The prevalence rate of Migraine obtained for an Iranian population was obtained as $14 \%$. This rate is higher than that reported by Lipton et al. in US (43), Radtke and Hannelore in Germany (44), and Ertas et al. in Turkey (45), but lower than that reported by Manandhar et al. in Nepal (46) and Rao et al. in India (47). The articles obtained from the subgroup were analyzed to evaluate the ratio of prevalence rate of migraine in the studied groups. In the current study, the prevalence rate of migraine among medical students was higher than that obtained by Ojini in Nigeria (48), and lower than that obtained by Bindu Menon and Kinnera in India (49), and Kurt and Kaplan (50). The difference in the prevalence rate of migraine in medical students obtained from various studies can be justified due to some reasons like diverse work methods or differences in the questionnaires used in studies. However, the greater number of females in the studies in comparison to the males could also be another reason for the prevalence of migraine in the students. Some stressful periods like midterm or final exams could also be responsible for the higher prevalence rate of migraine in the students. Racial and economic differences, climatic conditions, feeding habits and social situations may also be some factors which influenced the prevalence rate of migraine in the students (51). In different studies, the prevalence rate of migraine was investigated in medical students and ac- 


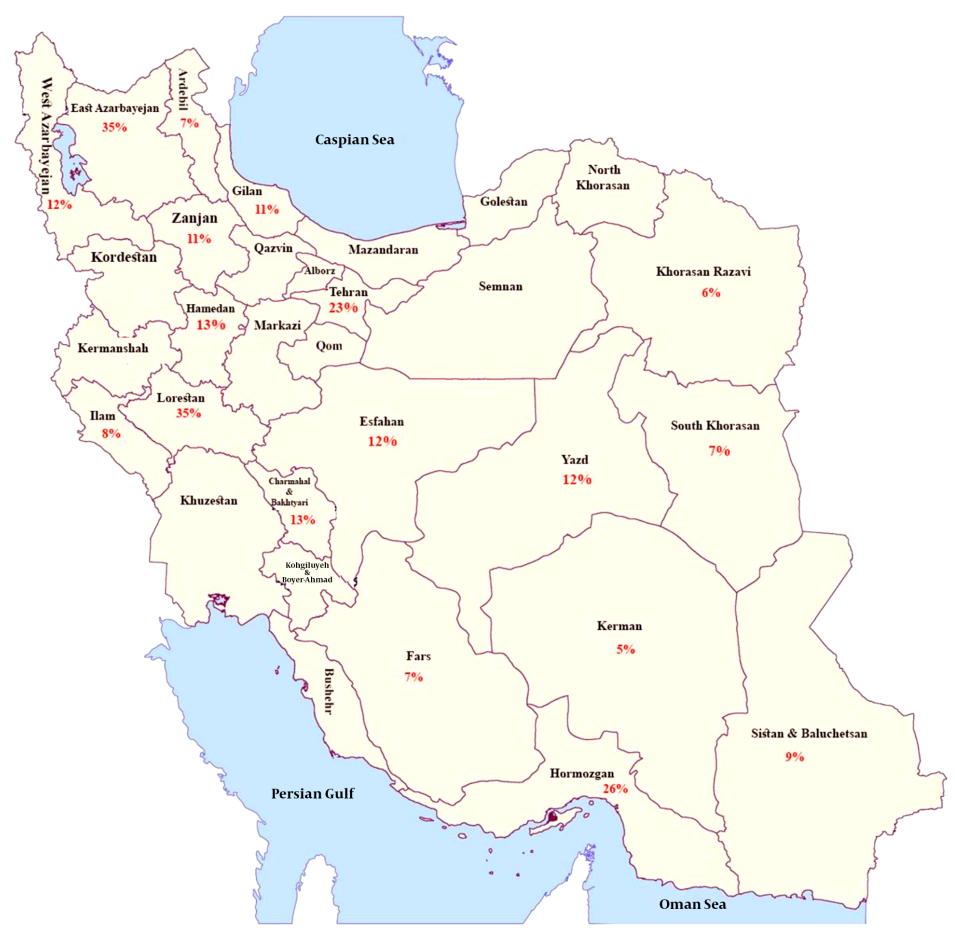

Figure 3. Graphic Representation of Overall Distribution of Migraine in the Provinces in Iran
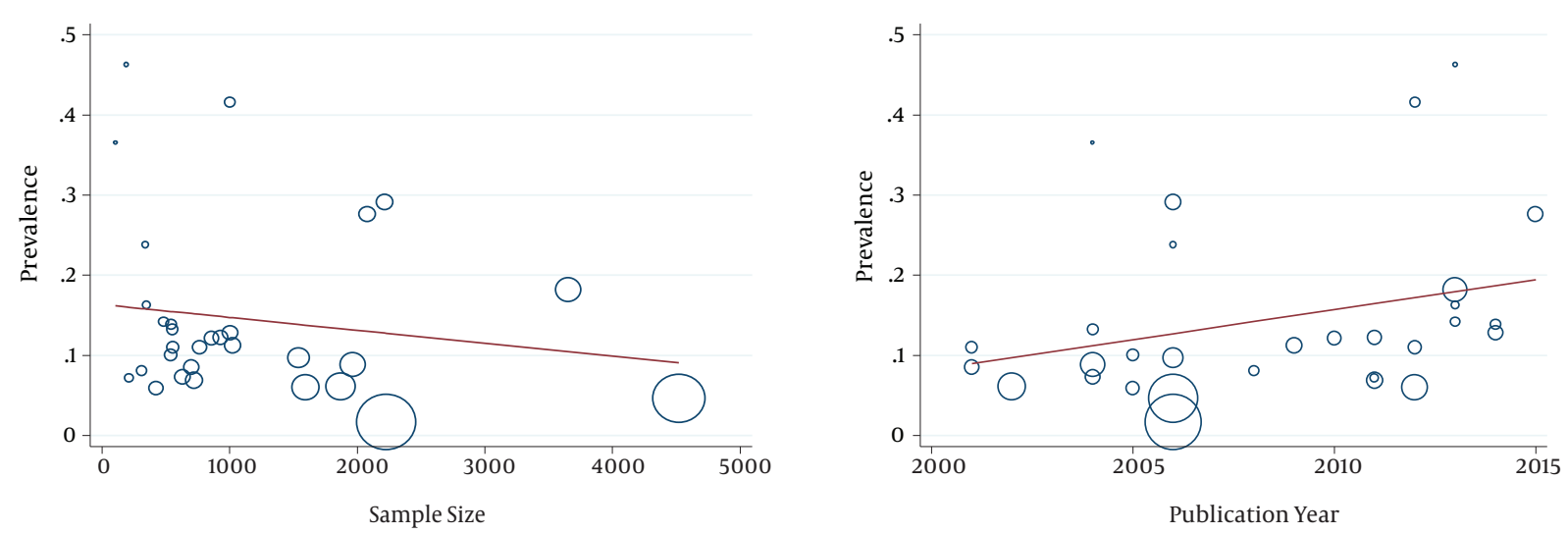

Figure 4. Association Between Prevalence by Publication of Year and Sample Size

cording to the results; the students were more likely to have migraines than any other non-medical students due to the environmentally and educationally stressful conditions $(52,53)$. Migraine in primary and high school students is often associated with complaints of headaches, and in many cases this issue prevents the students from attending schools, resulting to disability in daily activities. Iran is of a young population, and the identification of individuals who suffer from migraines can lead to the dis- covery of treatment which can help to make the patients an economically active workforce and more productive in the society. At the secondary and high schools ages, daily stresses faced by the students can lead to an increase in the risk of migraine. Stressful events for students commences from the beginning of school, and the expectations of parents from the students to attain the peak of academic achievements is another reason which can cause an increased incidence of migraine $(54,55)$. The inter- 


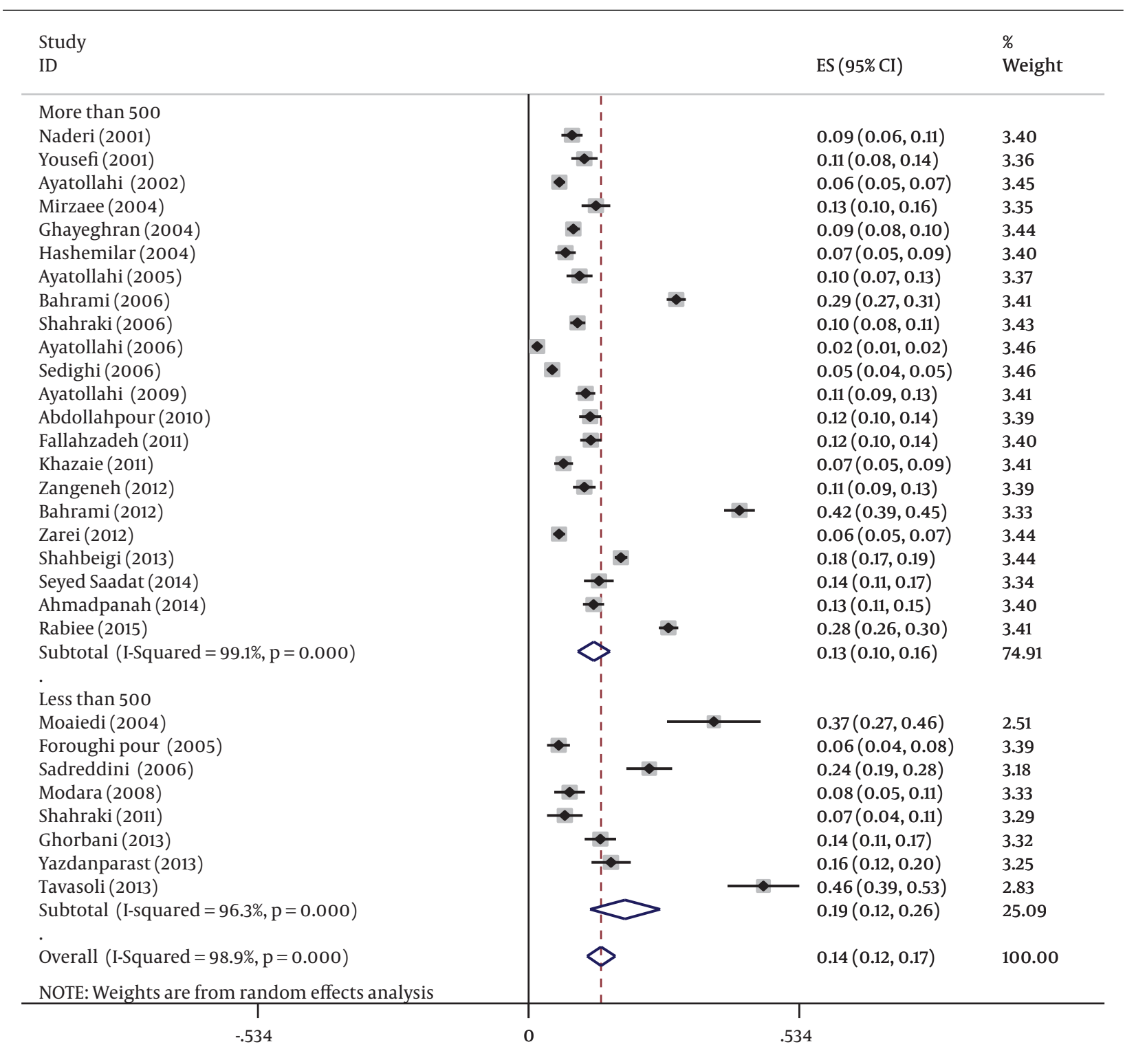

Figure 5. The Pooled Prevalence of Migraine in Iran Was Based on Sample Size

pretation of the prevalence with respect to different geographical areas in Iran showed high prevalence rate of migraine in the South and West (40\%). The southern regions in Iran are geographically tropical and the air temperature is very high. Daily activities and work-related stresses in hot and harsh conditions could be the reason for the increased prevalence of migraine in these areas. The Western regions in Iran are associated with cold weather, and cities in these areas often have large populations and lower economic levels. These conditions prevent people from meeting their financial needs. Hard physical activities and individual stresses could also be justifiable reasons for the prevalence of migraine in these areas. A number of studies have noted the relationship between vitamin D levels and the incidence of chronic pain (56). Some anecdotal evidences indicated that vitamin D may have a role in the incidence of headaches (57). The prevalence of migraine is worldwide and in different geographic areas (3). Many factors could be responsible for the differences in the ratio of prevalence of migraine in several countries. Some of these factors include cultures and also environmental and genetic conditions (58). The results of this study suggest that migraine is indeed influenced by climate, economic index and cultural factors. It seems that job conditions can 


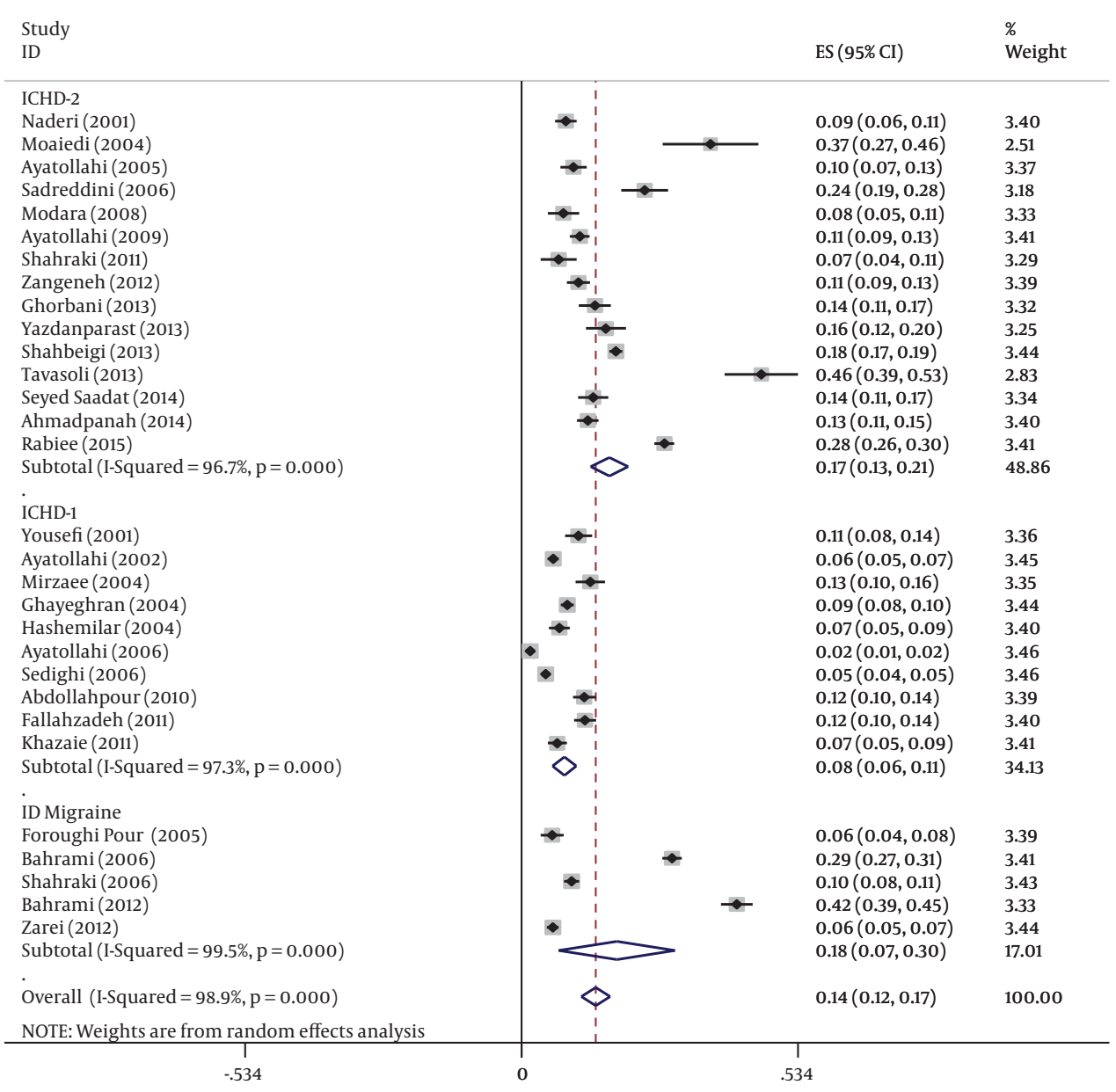

Figure 6. The Pooled Prevalence of Migraine in Iran Was Based on Diagnostic Criteria

either increase or decrease the prevalence of migraine in patients. Of course, this issue requires additional study. The results of the meta-regression indicated that there existed no significant relationship between the prevalence of migraine and the year of publication and sample size of the studies; however, Figure 4 shows a decreasing trend for the prevalence of migraine in Iran; although this was not found to be significant. These decreasing trends in countries might have resulted from factors like increased levels of quality of life and the promotion of educational programs and diagnostic methods for migraine, to mention a few. Notwithstanding, there may be unknown factors or changes in the known contributory factors over time.

A comparison of the prevalence of migraine in different regions of Iran indicated that it is widespread in the western ( $21 \%$ ), southern (19\%), central and north (11\%), and eastern $(8 \%)$ regions. It has been suggested that several social, climatic conditions, economic, and cultural factors may have effect on the prevalence of migraine. The differences in the prevalence of migraine between the various regions in Iran are therefore not surprising, given that the Iranian population exhibits cultural diversity and different economic index. It seems that the results of this study indicate that the living conditions can also have a great impact on the higher prevalence of migraine in the different groups of the society, such students. This agrees with the previous findings that migraine prevalence increases rapidly in studies regarding age.

One of the major advantages of this study is the huge sample size which is a valuable study in the field of evaluating the prevalence rate of migraine in Iran. Over the past years, in Iran, the prevalence of migraine in a population based on various studies in different provinces has been evaluated using a variety of methods performed by questionnaires and face to face interviews. The incongruity among 30 studies was analyzed. Some limitations of the 


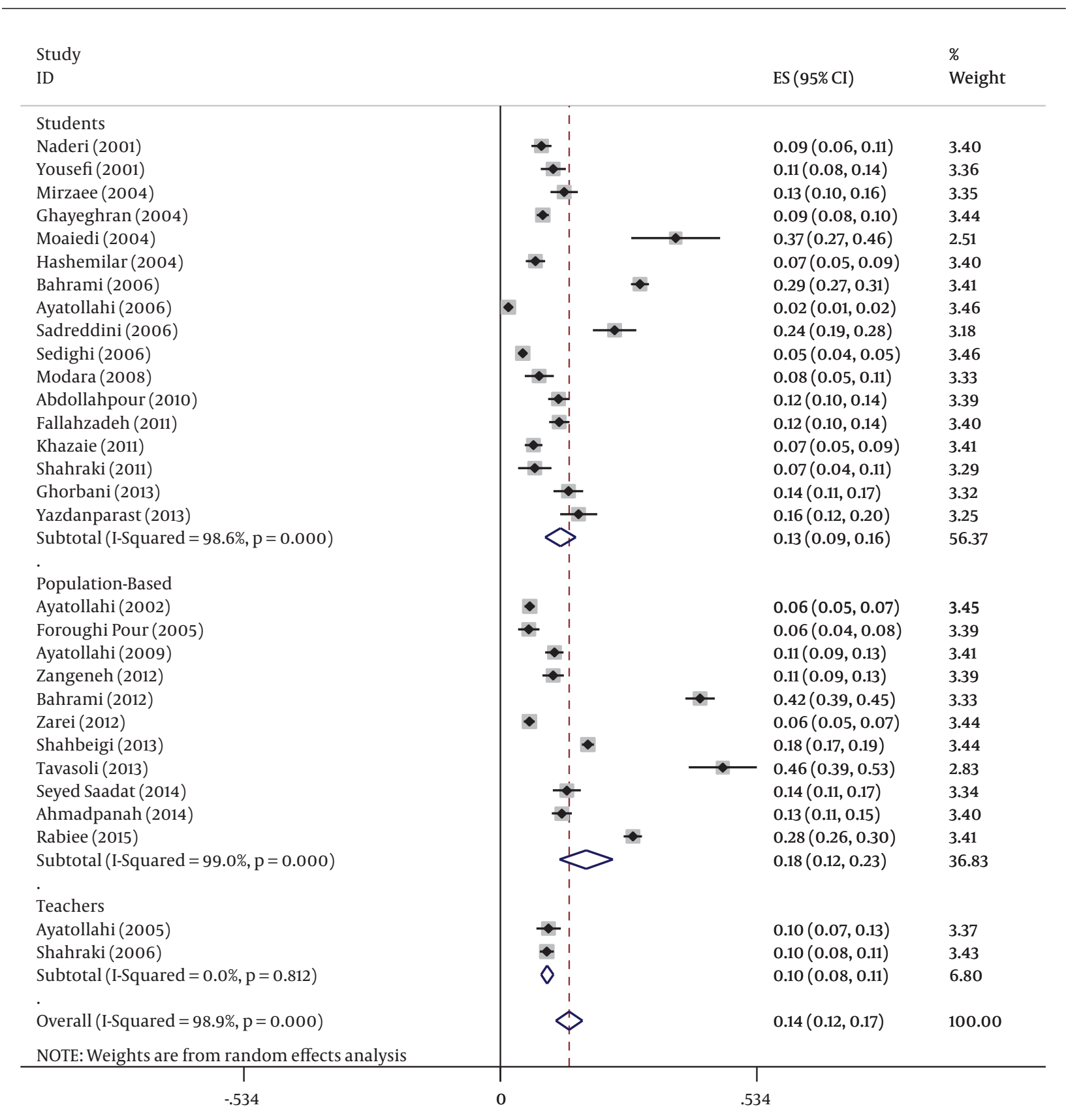

Figure 7. The Pooled Prevalence of Migraine in Iran Was Based on Groups of Participants

study are: in the present study, the methods of conducting the 30 studies entered into the analysis contained large variety, and the significant heterogeneity was identified among studies. This issue had effect on the accuracy of the results. Lack of consistency in the diagnostic criteria in some studies regarding the diagnosis of migraine was one of the important reasons for heterogeneity among studies.
Also, in some provinces of Iran, there existed no previous studies on the prevalence of migraine. There was no appropriate data according to gender and age in some studies. Under such conditions, the results of this study should be interpreted with caution.

In conclusion, migraine in Iran has an estimated prevalence of $14 \%$. The study showed that the prevalence of mi- 


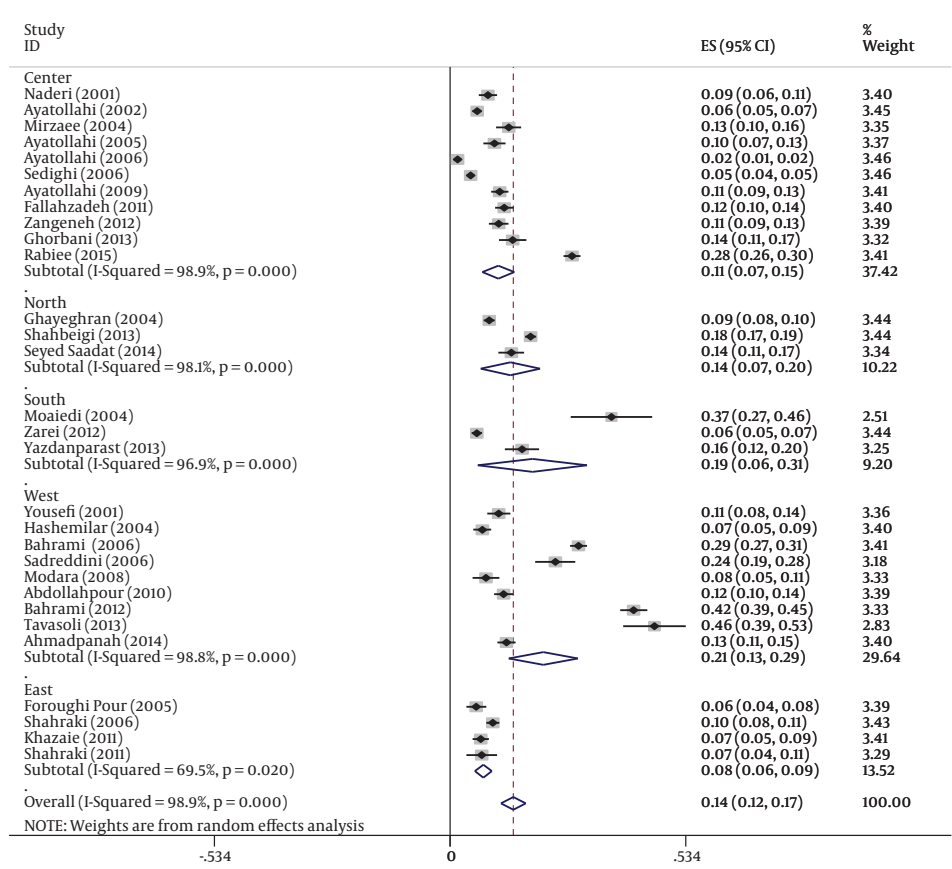

Figure 8. The Pooled Prevalence of Migraine in Iran Was Based on Geographical Region

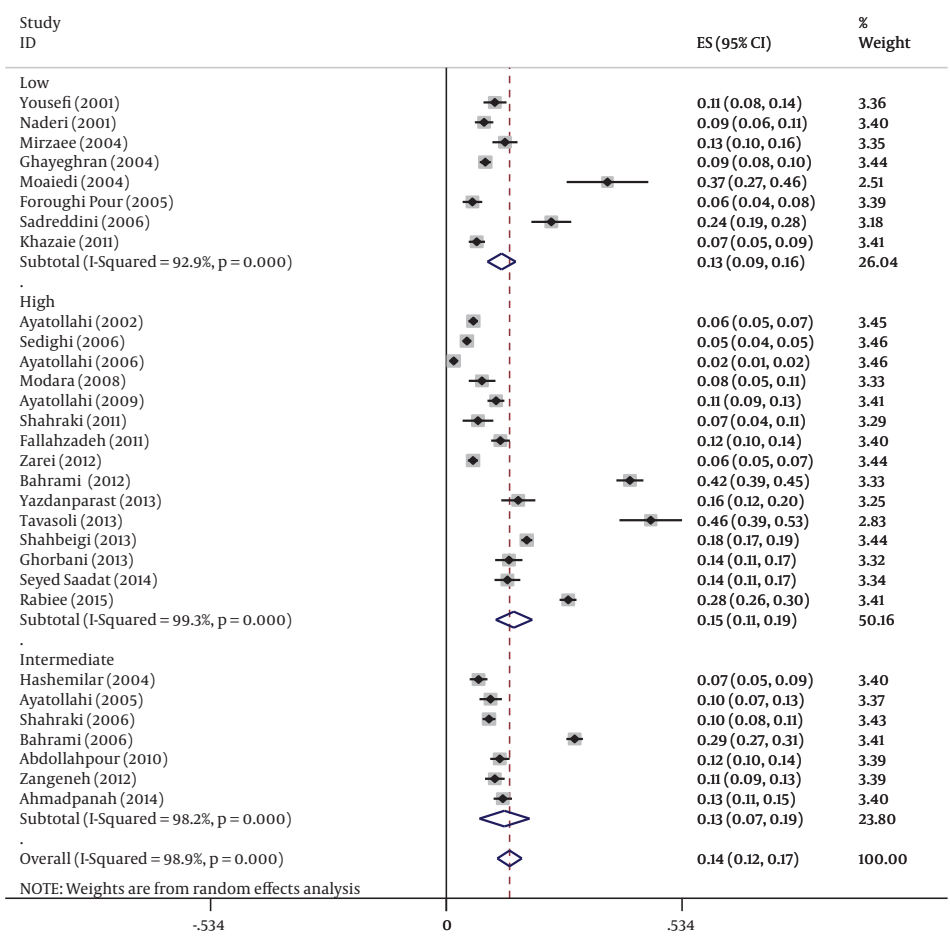

Figure 9. The Pooled Prevalence of Migraine in Iran Was Based on Quality of Studies 


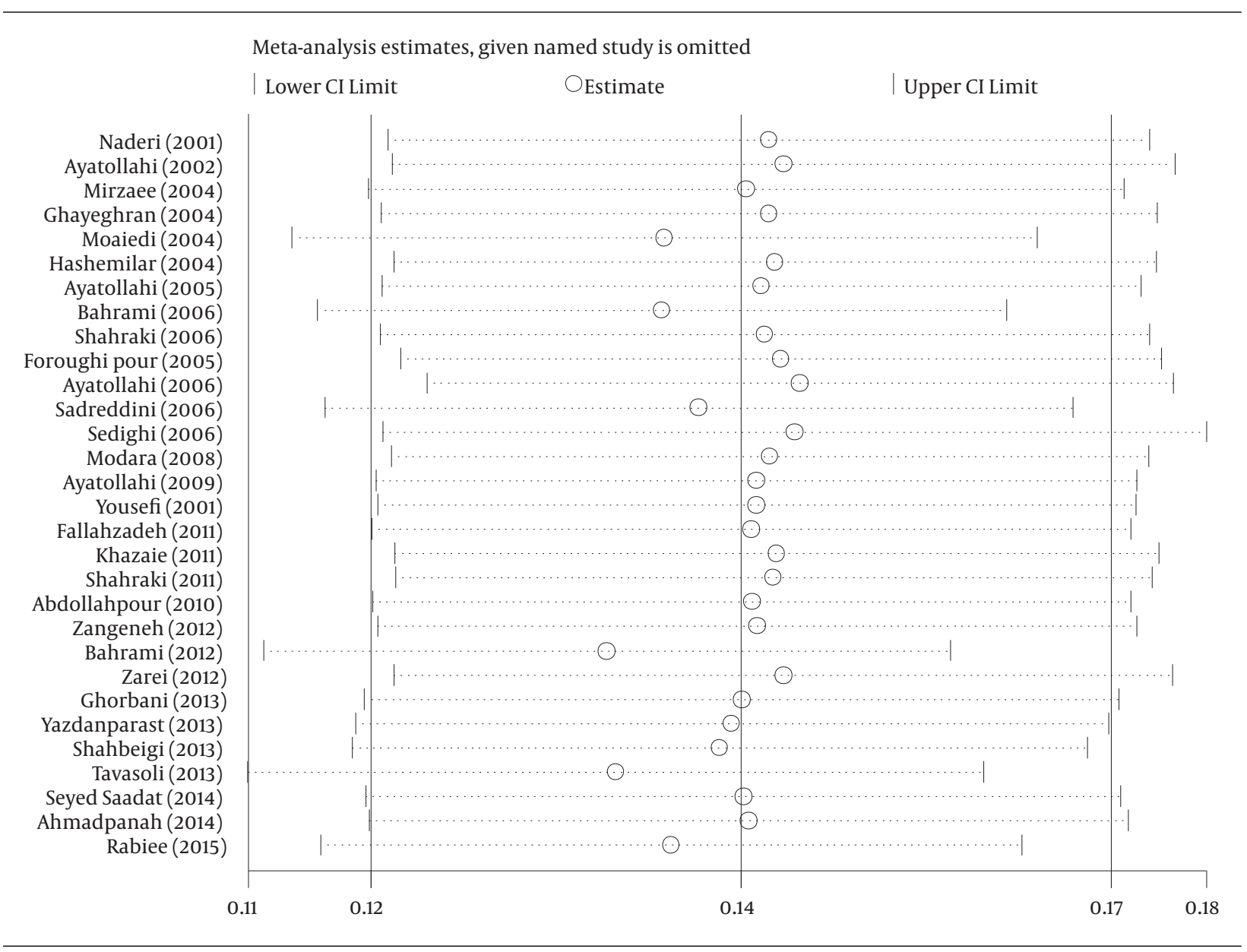

Figure 10. The Pooled Prevalence Sensivity Analysis of Migriane in Iran
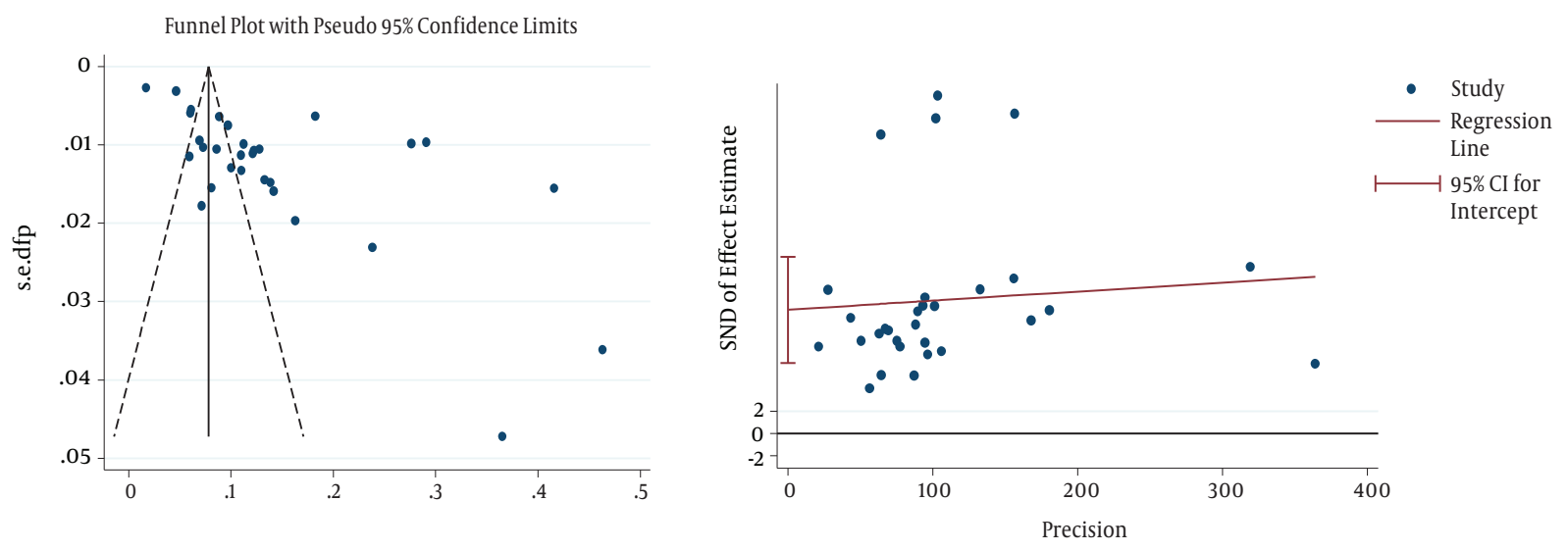

Figure 11. Funnel Plot and Egger Test to Assess Publication Bias

graine is high in Iran. Considering the impacts of migraine on economic productivity of any country, it seems necessary to train people for the early detection and obtaining of 
effective treatment of migraine. However, more studies are required to assess the prevalence of migraine in the population of Iran.

\section{Acknowledgments}

The authors are grateful to the reviewers for their constructive comments, which improved the manuscript.

\section{Footnote}

Authors' Contribution: Meysam Behzadifar, Hamid Ravaghi, Roghayeh Mohammadibakhsh, Masood Taheri Mirghaed, Morteza Salemi, Rahim Sohrabi, Zeynab Farhadi, Najmeh Khodadadi, Saeideh Alidoost, Razieh Sepehrian: data Collection and study design; Hamid Ravaghi, Masoud Behzadifar: final revision and grammar editing; Masoud Behzadifar: biostatical analysis.

\section{References}

1. Steiner TJ, Stovner LJ, Birbeck GL. Migraine: the seventh disabler. J Headache Pain. 2013;14:1. doi: 10.1186/1129-2377-14-1. [PubMed: 23566305].

2. Jensen R, Stovner LJ. Epidemiology and comorbidity of headache. Lancet Neurol. 2008;7(4):354-61. doi: 10.1016/S1474-4422(08)70062-0. [PubMed: 18339350].

3. Stovner L, Hagen K, Jensen R, Katsarava Z, Lipton R, Scher A, et al. The global burden of headache: a documentation of headache prevalence and disability worldwide. Cephalalgia. 2007;27(3):193-210. doi: 10.1111/j.1468-2982.2007.01288.x. [PubMed: 17381554].

4. Rasmussen BK. Epidemiology of headache. Cephalalgia. 2001;21(7):774-7. [PubMed: 11595011].

5. Lanteri-Minet M, Duru G, Mudge M, Cottrell S. Quality of life impairment, disability and economic burden associated with chronic daily headache, focusing on chronic migraine with or without medication overuse: a systematic review. Cephalalgia. 2011;31(7):837-50. doi: 10.1177/0333102411398400. [PubMed: 21464078].

6. Wahab KW, Ugheoke AJ. Migraine: prevalence and associated disability among Nigerian undergraduates. Can J Neurol Sci. 2009;36(2):21621. [PubMed: 19378718].

7. Lima AM, Sapienza GB, Giraud Vde O, Fragoso YD. Odors as triggering and worsening factors for migraine in men. Arq Neuropsiquiatr. 2011;69(2B):324-7. [PubMed: 21625759].

8. Global Burden of Disease Study C. Global, regional, and national incidence, prevalence, and years lived with disability for 301 acute and chronic diseases and injuries in 188 countries, 1990-2013: a systematic analysis for the Global Burden of Disease Study 2013. Lancet. 2015;386(9995):743-800. doi: 10.1016/S0140-6736(15)60692-4. [PubMed: 26063472].

9. Liberati A, Altman DG, Tetzlaff J, Mulrow C, Gotzsche PC, Ioannidis JP, et al. The PRISMA statement for reporting systematic reviews and meta-analyses of studies that evaluate healthcare interventions: explanation and elaboration. BMJ. 2009;339:b2700. doi: 10.1136/bmj.b2700. [PubMed: 19622552].

10. von Elm E, Altman DG, Egger M, Pocock SJ, Gotzsche PC, Vandenbroucke JP, et al. The Strengthening the Reporting of Observational Studies in Epidemiology (STROBE) statement: guidelines for reporting observational studies. Bull World Health Organ. 2007;85(11):867-72. [PubMed: 18038077].
11. Higgins JP, Thompson SG, Deeks JJ, Altman DG. Measuring in consistency in meta-analyses. BMJ. 2003;327(7414):557-60. doi: 10.1136/bmj.327.7414.557. [PubMed: 12958120].

12. Egger M, Davey Smith G, Schneider M, Minder C. Bias in meta-analysis detected by a simple, graphical test. BMJ. 1997;315(7109):629-34 [PubMed: 9310563].

13. Naderi T, Hamzehie-Moghadam A, Bahrampour A. Prevalence of migraine and its related factors in female students with premenstural syndrom [in Persian]. Scie J Kurdistan Uni Med Sci. 2000;5(1):18-22.

14. Yousefi M. Prevalence of migraine in medical students and doctors, Zanjan University of medical sciences. Zanjan Uni Med Sci. 1999;8(30):18-22.

15. Ayatollahi SM, Moradi F, Ayatollahi SA. Prevalences of migraine and tension-type headache in adolescent girls of Shiraz (southern Iran). Headache. 2002;42(4):287-90. [PubMed: 12010386].

16. Ghayeghran AF. Survey on Prevalence of Migraine in Highschool Students of Rasht- City. J Guilan Uni Med Sci. 2004;13(50):22-6.

17. Hashemilar M, Aminisani N, Savadi Oskoui D, Yosefian M. The Prevalence of Migraine Among Student of Ardabil University of Medical Sciences, 2003. J Ardebbil Uni Med Sci. 2004;4(1):64-9.

18. Mirzaee MG. A review of cammon migraine in girls high school and related fall in education in Shahrekord region.J Shahrekord Univ Med Sci. 2004;5(4):55-62.

19. Moaiedi AR. Causes of headache in patients referring to Bandar Abbas pediatric hospital. Hormozgan Med J. 2004;8(2):73-6.

20. Ayatollahi SM. An Epidemiologic Model for Risk Factors of Migraine and Tension type Headaches among Primary Schools Teachers of Shiraz, 2003. J Kerman Uni Med Sci. 2005;12(2):85-92.

21. Foroughipour MR, Raziei MB, Faraji M, Rezaei Talab F, Saberi S. Evaluation of the causes of headache in patients referred to neurological clinic of Ghaem Hospital. Iran J Otorhinolaryngol. 2006;17(39):64-9.

22. Ayatollahi SM, Khosravi A. Prevalence of migraine and tension-type headache in primary-school children in Shiraz. East Mediterr Health J. 2006;12(6):809-17. [PubMed: 17333827].

23. Bahrami P. Incidence of Migraine in high school students in Khorramabad. Yafteh. 2006;7(1):55-60.

24. Sadreddini SA, Talebi M. Assessment of Prevalence and Type of Headache in Medical Students. J Tabriz Uni Med Sci Health Serv. 2006;28:73-9.

25. Sedighi B, Ghaderi-Sohi S, Emami S. Evaluation of self-medication prevalence, diagnosis and prescription in migraine in Kerman, Iran. Saudi Med J. 2006;27(3):377-80. [PubMed: 16532101].

26. Shahraki MR, Moghtaderi A, Mirshekari H. The study of prevalence of migraine among teachers at Zahedan, Iran. J Zahedan Res Med Sci. 2006;8(2):137-42.

27. Modara FR, Rostamkhani M. Prevalence of tension and migraine headachesamong the students of Ilam Medical University.J Ilam Uni Med Sci. 2008;15(4):13-21.

28. Ayatollahi SM, Haghighi AB. Epidemiologic and Clinical Characteristics of Migraine and Tension-Type Headaches among Hospitals Staffs of Shiraz (Iran). Acta Med Iran. 2009;47(2):115-20.

29. Abdollahpour I, Salimi Y, Jabbedari B, Hajji M, Jarjaran Shoshtari Z. Prevalence of Migraine and its Triggers in High School Student in Boukan. Urumia Med J. 2013;23(6):661-9.

30. Fallahzadeh H, Alihaydari M. Prevalence of migraine and tensiontype headache among school children in Yazd, Iran.J Pediatr Neurosci. 2011;6(2):106-9. doi: 10.4103/1817-1745.92818. [PubMed: 22408655].

31. Khazaie T, Dehghani Firoozabadi M, Sharifzadeh R. Prevalence of migraine and its relationship to educational performance in adolescents of Brijand city (2010).J Jirjand Uni Med Sci. 2011;18(2):94-101.

32. Shahrakai MR, Mirshekari H, Ghanbari AT, Shahraki AR, Shahraki E. Prevalence of Migraine Among Medical Students in Zahedan Faculty of Medicine (Southeast of Iran). Basic Clin Neurosci. 2011;2(2):20-5. 
33. Bahrami P, Zebardast H, Zibaei M, Mohammadzadeh M, Zabandan N Prevalence and characteristics of headache in Khoramabad, Iran.Pain Physician. 2012;15(4):327-32. [PubMed: 22828686].

34. Zangeneh FA, Najafi MR, Norouzi R. Epidemiologic and Clinical Characteristics of Migraine Headaches:A Descriptive Study in Isfahan Iran. J Isfahan Med School. 2012;30(187):1-7.

35. Zarei S, Bigizadeh S, Pourahmadi M, Ghobadifar MA. Chronic Pain and Its Determinants: A Population-based Study in Southern Iran. Korean JPain. 2012;25(4):245-53. doi: 10.3344/kjp.2012.25.4.245. [PubMed 23091685].

36. Ghorbani A, Abtahi SM, Fereidan-Esfahani M, Abtahi SH, Shemshaki $\mathrm{H}$, Akbari M, et al. Prevalence and clinical characteristics of headache among medical students, Isfahan, Iran. J Res Med Sci. 2013;18(Suppl 1):24-7. [PubMed: 23961279].

37. Shahbeigi S, Fereshtehnejad SM, Mohammadi N, Golmakani MM, Tadayyon S, Jalilzadeh G, et al. Epidemiology of headaches in Tehran urban area: a population-based cross-sectional study in district 8 year 2010. Neurol Sci. 2013;34(7):1157-66. doi: 10.1007/s10072-012-12000. [PubMed: 23010877].

38. Tavasoli A, Aghamohammadpoor M, Taghibeigi M. Migraine and tension-type headache in children and adolescents presenting to neurology clinics. Iran J Pediatr. 2013;23(5):536-40. [PubMed: 24800013].

39. Yazdanparast M, Abrishamizadeh AA, Mahboobi H, Omrani A, Ghasemi M, Ghorashi M, et al. Prevalence of and Factors Associated with Migraine in Medical Students at BandarAbbas, Southern Iran, in 2012. Electron Physician. 2013;5(3):679-84. doi: 10.14661/2013.679-684 [PubMed: 26120402].

40. Ahmadpanah M, Ghaderzadeh P. Investigation of prevalence and clinical characteristics of migraine patients referred to the neurology department of Sina Hospital, 2010. Pajouhan Scien J. 2014;12(4):1-6.

41. Seyed Saadat SM, Hosseininezhad M, Bakhshayesh B, Hoseini M Naghipour M. Epidemiology and clinical characteristics of chronic daily headache in a clinic-based cohort of Iranian population. Neurol Sci. 2014;35(4):565-70. doi: 10.1007/s10072-013-1550-2. [PubMed 24068481].

42. Rabiee B, Zeinoddini A, Kordi R, Yunesian M, Mohammadinejad P, Mansournia MA. The Epidemiology of Migraine Headache in General Population of Tehran, Iran. Neuroepidemiology. 2016;46(1):9-13. doi: 10.1159/000441146. [PubMed: 26580919].

43. Lipton RB, Bigal ME, Diamond M, Freitag F, Reed ML, Stewart WF, et al. Migraine prevalence, disease burden, and the need for preventive therapy. Neurology. 2007;68(5):343-9. doi: 10.1212/01.wnl.0000252808.97649.21. [PubMed: 17261680].

44. Radtke A, Neuhauser H. Prevalence and burden of headache and migraine in Germany. Headache. 2009;49(1):79-89. doi: 10.1111/j.15264610.2008.01263.x. [PubMed: 19125877].

45. Ertas M, Baykan B, Orhan EK, Zarifoglu M, Karli N, Saip S, et al. One-year prevalence and the impact of migraine and tension-type headache in Turkey: a nationwide home-based study in adults. J Headache Pain.
2012;13(2):147-57. doi: 10.1007/s10194-011-0414-5. [PubMed: 22246025]. 46. Manandhar K, Risal A, Steiner TJ, Holen A, Linde M. The prevalence of primary headache disorders in Nepal: a nationwide populationbased study. J Headache Pain. 2015;16:95. doi: 10.1186/s10194-015-0580y. [PubMed: 26554602].

47. Rao GN, Kulkarni GB, Gururaj G, Rajesh K, Subbakrishna DK, Steiner TJ, et al. The burden of headache disorders in India: methodology and questionnaire validation for a community-based survey in Karnataka State. J Headache Pain. 2012;13(7):543-50. doi:10.1007/s10194-012-04741. [PubMed: 22911168].

48. Ojini FI, Okubadejo NU, Danesi MA. Prevalence and clinical characteristics of headache in medical students of the University of Lagos, Nigeria. Cephalalgia. 2009;29(4):472-7. doi: 10.1111/j.14682982.2008.01766.x. [PubMed: 19170698].

49. Menon B, Kinnera N. Prevalence and characteristics of migraine in medical students and its impact on their daily activities. Ann Indian Acad Neurol. 2013;16(2):221-5. doi: 10.4103/0972-2327.112472. [PubMed: 23956569].

50. Kurt S, Kaplan Y. Epidemiological and clinical characteristics of headache in university students. Clin Neurol Neurosurg. 2008;110(1):46-50. doi: 10.1016/j.clineuro.2007.09.001. [PubMed: 17949895].

51. Nandha R, Chhabra MK. Prevalence and clinical characteristics of headache in dental students of a tertiary care teaching dental hospital in Northern India. Int J Basic Clin Pharmacol. 2013;2(1):51-5. doi: 10.5455/2319-2003.ijbcp20130110.

52. Ferri-de-Barros JE, Alencar MJ, Berchielli LF, Castelhano Junior LC. Headache among medical and psychology students. Arq Neuropsiquiatr. 2011;69(3):502-8. [PubMed: 21755130].

53. Ezeala-Adikaibe AB, Stella EO, Ikenna O, Ifeoma U. Frequency and pattern of headache among medical students at Enugu, South East Nigeria. Niger J Med. 2012;21(2):205-8. [PubMed: 23311192].

54. Karli N, Akis N, Zarifoglu M, Akgoz S, Irgil E, Ayvacioglu U, et al. Headache prevalence in adolescents aged 12 to 17: a student-based epidemiological study in Bursa. Headache. 2006;46(4):649-55. doi: 10.1111/j.1526-4610.2006.00362.x. [PubMed:16643560].

55. Laurell K, Larsson B, Mattsson P, Eeg-Olofsson O. A 3-year follow-up of headache diagnoses and symptoms in Swedish schoolchildren. Cephalalgia. 2006;26(7):809-15. doi: 10.1111/j.1468-2982.2006.01113.x. [PubMed: 16776695].

56. Straube S, Andrew Moore R, Derry S, McQuay HJ. Vitamin D and chronic pain. Pain. 2009;141(1-2):10-3. doi: 10.1016/j.pain.2008.11.010. [PubMed: 19084336].

57. Prakash S, Shah ND. Chronic tension-type headache with vitamin D deficiency: casual or causal association?. Headache. 2009;49(8):121422. doi: 10.1111/j.1526-4610.2009.01483.x. [PubMed: 19619241].

58. Prakash S, Mehta NC, Dabhi AS, Lakhani O, Khilari M, Shah ND. The prevalence of headache may be related with the latitude: a possible role of Vitamin D insufficiency?.J Headache Pain. 2010;11(4):301-7. doi: 10.1007/s10194-010-0223-2. [PubMed: 20464624]. 